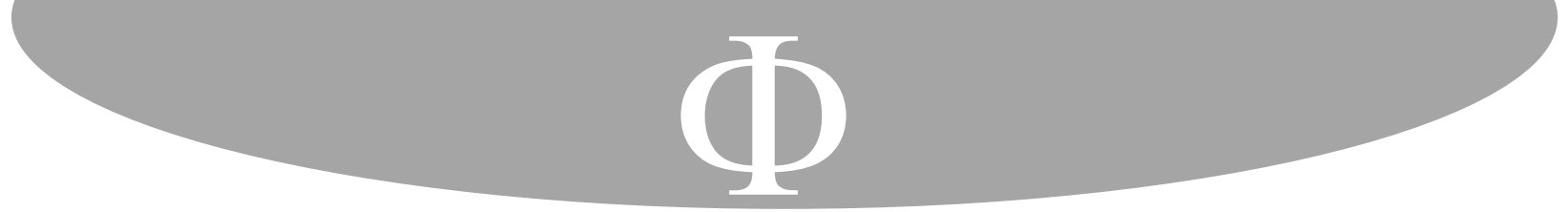

\title{
La virtud del desprendimiento o señorío según Leonardo Polo
}

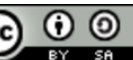

Juan Fernando Sellés*

Universidad de Navarra

Navarra, España

\begin{abstract}
Para citar este artículo: Sellés, Juan Fernando. «La virtud del desprendimiento o señorío según L. Polo».
Franciscanum 175, Vol. 63 (2021): 1-13.
\end{abstract}

\section{Resumen}

Teniendo en cuenta los tres niveles jerárquicamente distintos que Leonardo Polo distingue en el hombre, naturaleza corpórea, esencia inmaterial (inteligencia, voluntad y personalidad) y acto de ser personal, la pobreza puede afectar a una u otra capa; y su gravedad es distinta según afecte a una u otra. Individualismo, igualitarismo, masificación, subjetivismo y avaricia son causas de ella. Son motivos de desprendimiento: adquirir la virtud, crecer íntimamente, favorecer a los demás y destinarse a Dios.

\section{Palabras clave}

Desprendimiento, virtud, crecimiento, motivos, Leonardo Polo.

\section{The virtue of detachment or dominion according to Leonardo Polo}

\begin{abstract}
Based on the three hierarchically different levels that Leonardo Polo distinguishes in man, corporeal nature, immaterial essence (intelligence, will and personality) and the act of being personal, the poverty can affect one or another layer; and its degree of severity is different according to how it affects one or another. Individualism, egalitarianism, massification, subjectivism and avarice are causes of it. They are causes of detachment: to achieve virtue, to grow intimately, to favor others and to be destined to God.
\end{abstract}

\section{Key words}

Detachment, virtue, growth, motives, Leonardo Polo.

\footnotetext{
* Doctor en Filosofía por la Universidad de Navarra y profesor del Departamento de Filosofía en dicha institución académica. Ha sido Profesor Visitante de diversas universidades extranjeras. Sus dos líneas de investigación son la Antropología filosófica y la Teoría del conocimiento. Contacto: jfselles@unav.es. ORCID: https://orcid.org/0000-0003-1839-1276.
} 


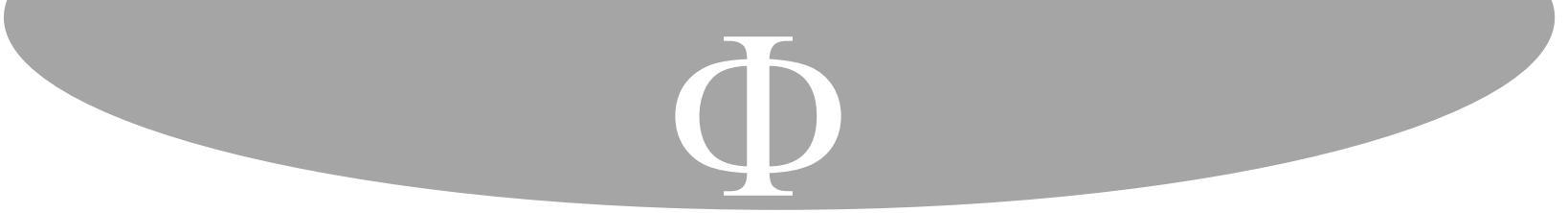

\section{Planteamiento}

La pobreza se puede decir de muchas maneras, e incluso con sentidos opuestos, negativo y positivo. Constitutivamente el hombre es pobre, necesitado, solo a nivel corpóreo, pero es muy rico, desbordante, a nivel personal o de acto de ser, y eso desde el inicio de su existencia. Dicho en lenguaje aristotélico: a nivel corpóreo somos en exceso potenciales, pero a nivel personal somos demasiado activos, actividad que, con el paso del tiempo, manifestamos sin restricción la esencia del hombre -inteligencia, voluntad y personalidad-, y derivada y limitadamente en nuestras acciones corpóreas. Por eso, a nivel corpóreo «el hombre es un ser nacido en y de la pobreza, pero llamado a fecundarla en la abundancia; un ser cruzado de indigencia y trascendencia, que no se aquieta en aquélla, pues a la vez se impulsa a ir "más allá del límite" ..., esto es, a trascenderse» ${ }^{1}$. La pobreza de nuestro tener corpóreo es remediada a lo largo de la vida por el interés de la razón práctica: «Estar entre entes en el mundo, es estar justamente en situación de pobreza; en ella se monta el interés mismo, el no tener otro remedio que interesarnos trenzando con el interés a los entes» ${ }^{2}$, resolver nuestras deficiencias hasta el punto de procurarnos superabundancia de bienes.

Téngase en cuenta que la visión del hombre como ser enteramente pobre al inicio de su vida no es propia de la filosofía clásica griega y medieval, sino de la moderna y contemporánea, que es justo la inversa a aquélla, pues en la modernidad se empieza a considerar que el hombre es inicialmente por entero potencial, deficiente, por lo que tiene que acaparar perfección progresivamente, postulando que desde el estado inicial de menesterosidad al estado definitivo de perfección el hombre pasará activándose «espontáneamente», lo cual es injustificable, porque de lo inferior y menos perfecto no puede surgir lo superior y más perfecto ${ }^{3}$. Además, lo que es al inicio enteramente potencial, pasivo, en nosotros, como son las facultades de la inteligencia y de la voluntad, es claro que no se pueden activar ni por lo inferior, el cuerpo humano, ni por ellas mismas, sino por una realidad activa superior a ellas, a saber, la persona humana, la cual es nativamente activa (libertad, conocimiento personal, amar personal ${ }^{4}$ ). Algo similar a lo postulado por la filosofía moderna

\footnotetext{
${ }^{1}$ F. Altarejos, «Introducción», en L. Polo, Ayudar a crecer. Cuestiones de filosofía de la educación (Pamplona: Eunsa, col. Astrolabio, 2006), 16.

${ }^{2}$ L. Polo, «Curso de psicología general», en Obras Completas, Vol. XXI (Pamplona: Eunsa, 2018), 74. Cf. sobre el tener humano: J.J. Padial, «La antropología del tener según Leonardo Polo», Cuadernos de Anuario Filosófico 100 (2000): 1-146.

${ }^{3}$ «En la teoría clásica, el hombre es optimable porque no hay primero un dinamismo pobre, desnudo: así el óptimo es posible y no utópico. En cambio, si el hombre es un dinamismo que se configura posterior o especularmente tan sólo, el óptimo se pierde, es inasequible: lo ulterior es, como perfección, irreal. Con otras palabras, si la forma es primera como ulterior no hay nada que hacer respecto de un óptimo». L. Polo, «Presente y futuro del hombre», en Obras Completas, Vol. X (Pamplona: Eunsa, 2015), 299. Sobre esta temática histórica contamos con mucha bibliografía de autores polianos, pero a título de ejemplo pueden servir los tres números monográficos de la revista Studia Poliana dedicados a diversos autores centrales de la historia del pensamiento occidental, a saber, los números 5, 6 y 7 de los años 2003, 2004 y 2005, respectivamente.

${ }^{4}$ Cf. L. Polo, «Antropología trascendental», en Obras Completas, Vol. XV (Pamplona: Eunsa, 2015), $229-278$. Escritos polianos sobre este punto los hay en abundancia. Cf., por ejemplo, S. Piá-Tarazona, El hombre como ser dual (Pamplona: Eunsa, 2001); J.F. Sellés, Antropología para inconformes (Madrid: Rialp, 2012); J.F. Sellés, Antropología de la intimidad (Madrid: Rialp, 2013); J.F. Sellés, Estudios sobre la antropología
} 


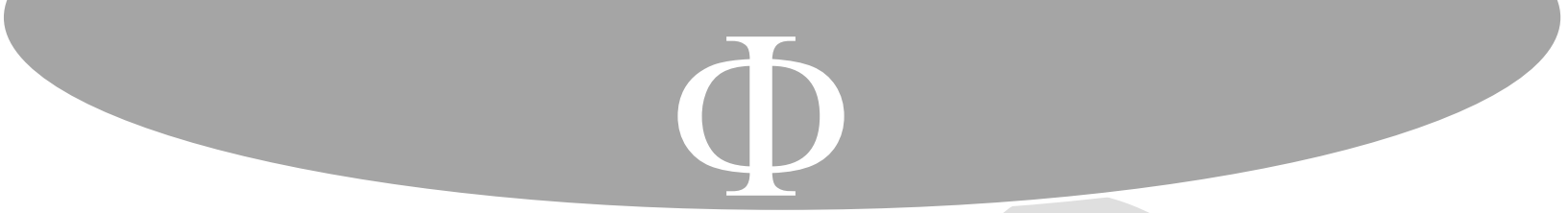

colaboración entre personas distintas con distinciones tipológicas y división de funciones tanto en la familia como en la sociedad ${ }^{8}$. En rigor, la verdadera riqueza humana, el crecimiento humano, se opone al individualismo, que es la negación del ser humano: «El hombre está llamado a la vida social porque es dialógico y el mundo que organiza es un mundo común. El hombre aislado, marginado, no pertenece al plexo. Nadie le llama a formar parte de la complejidad de los asuntos humanos, y ello le empobrece como existente, porque le priva de autoría en orden al mundo, que se caracteriza por la interrelación» 9 . Individualismo es aislamiento, y las virtudes humanas no crecen sin el roce con nuestros semejantes: «la tragedia de la persona es su aislamiento, pues en esa situación su libertad esencial se empobrece» ${ }^{10}$. Por su parte, la pobreza material no se opone a la riqueza personal, sino que radica en considerar a todas las personas «iguales» en sus tipos y funciones y verlas como independientes, pues de esa manera nadie colabora con nadie, nadie se beneficia de lo que otro aporta, y consecuentemente el bien común no se incrementa.

Empobrecer la razón se puede hacer de muchas maneras. Aunque parezca paradójico, para Polo «la filosofía moderna empieza en Descartes con un voto de pobreza en materia intelectual» ${ }^{11}$. En nuestros días, esa reducción no solo ha aumentado respecto del tema superior, sino que también se acrecienta en los diversos métodos usuales de pensamiento ${ }^{12}$. Esta pereza mental se traduce en una limitación de la libertad, lo cual empobrece a la persona

\footnotetext{
8 «La clave de la sociedad no es la economía o la biología, sino la integración de los distintos tipos humanos. Si esto no se logra, es decir, si cada tipo humano se incomunica y se recaba como absoluto, la productividad social se empobrece». L. Polo, «Nominalismo, idealismo y realismo», en Obras Completas, Vol. XIV (Pamplona: Eunsa, 2015), 148.

${ }^{9}$ L. Polo, «Antropología de la acción directiva», 325.

${ }^{10}$ L. Polo, «Antropología trascendental», 288.

${ }^{11}$ L. Polo, «Evidencia y realidad en Descartes», en Obras Completas, Vol. I (Pamplona: Eunsa, 2016), 102, nota 10. En otro lugar añade: Si se le pregunta a qué obedece este recortar las alas de la inteligencia, su respuesta no deja lugar a dudas: «la Edad Moderna ha hecho un voto de pobreza en materia de conocimiento; pero la inteligencia es probablemente una facultad a la que no conviene este tipo de voto; como el tema de Dios es el más alto, cualquier disminución o falta de ejercicio de la inteligencia introduce una dificultad artificial, sumamente desaconsejable». L. Polo, «Presente y futuro del hombre», 303.

12 Por ejemplo, en este: «una de las manifestaciones que a este empobrecimiento humano cabe atribuir la encontramos en el estilo del pensamiento de nuestra época, en lo que yo llamaría la "manía" por la combinatoria. Cuando uno dispone de un ámbito muy enrarecido y disperso de elementos significativos, prácticamente lo único que puede hacer es combinar lo que tiene, establecer una especie de juego en que una serie de elementos se asocian de una manera más o menos caleidoscópica. Si examinamos lo que pasa hoy en amplias zonas del pensamiento - por dónde va la Sociología, la Biología genética, la Teoría de la Cultura, por dónde va el Cálculo matemático operacional, incluso la misma Lógica-, se ve muy claro que, en muchas ocasiones, las construcciones teóricas se reducen a una combinatoria. Pero desde el punto de vista de la consideración del hombre como ser que se personaliza, ¿qué es la combinatoria? Simplemente, aquella situación de extrema pobreza de recursos mentales, en que lo único que se puede hacer con ellos es combinarlos, jugar con ellos, componiéndolos de un modo u otro». L. Polo, «La persona humana y su crecimiento», en Obras Completas, Vol. XIII (Pamplona: Eunsa, 2015), 31.
} 


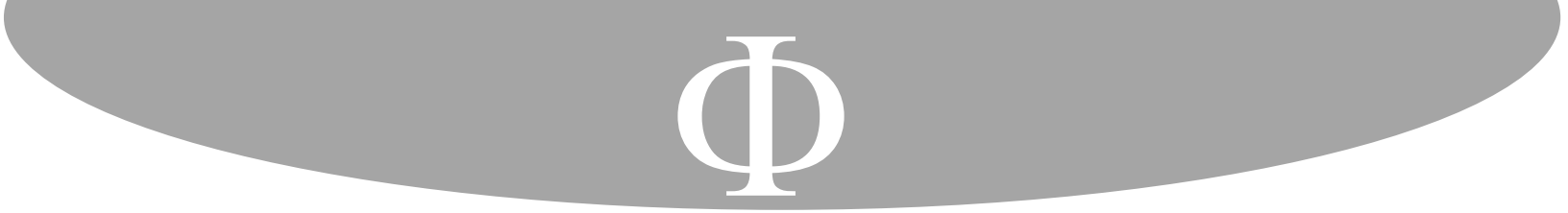

Polo, L. «Epistemología, creación y divinidad». En Obras Completas, Vol. XXVII. Pamplona: Eunsa, 2015.

Polo, L. «Ética: hacia una versión moderna de los temas clásicos». En Obras Completas Vol. XI. Pamplona: Eunsa, 2018.

Polo, L. «Evidencia y realidad en Descartes». En Obras Completas, Vol. I. Pamplona: Eunsa, 2016.

Polo, L. «Filosofía y economía». En Obras Completas, Vol. XXV. Pamplona: Eunsa, 2015.

Polo, L. «Introducción a la fillosofía». En Obras Completas, Vol. XII. Pamplona: Eunsa, 2015

Polo, L. «La esencia del hombre». En Obras Completas. Pamplona: Eunsa, 2015.

Polo, L. «La originalidad de la concepción cristiana de la existencia». En Obras Completas, Vol. XIII. Pamplona: Eunsa, 2015.

Polo, L. «La persona humana y su crecimiento». En Obras Completas, Vol. XIII. Pamplona: Eunsa, 2015.

Polo, L. «Nietzsche como pensador de dualidades». En Obras Completas, Vol. XVII. Pamplona: Eunsa, 2018.

Polo, L. «Nominalismo, idealismo y realismo». En Obras Completas, Vol. XIV. Pamplona: Eunsa, 2015.

Polo, L. «Persona y libertad». En Obras Completas, Vol. XIX. Pamplona: Eunsa, 2017.

Polo, L. «Presente y futuro del hombre». En Obras Completas, Vol. X. Pamplona: Eunsa, 2015.

Rodríguez Sedano, A. Libertad y actividad. Pamplona: Eunsa, 2018.

Sellés, J.F. Antropología de la intimidad. Madrid: Rialp, 2013.

Sellés, J.F. Antropología para inconformes. Madrid: Rialp, 2012.

Sellés, J.F. ed. El hombre como solucionador de problemas. Pamplona: Servicio de Publicaciones de la Universidad de Navarra, 2015.

Sellés, J.F. Estudios sobre la antropología trascendental de L. Polo. Salamanca: Sindéresis, 2019.

Sellés, J.F. Teología para inconformes. Madrid: Rialp, 2019.

Solomiewich, A. «Una discusión de la tesis de Salvador Piá "el aceptar es inferior al dar"». Miscelanea Poliana 67 (2020): 161-173.

Vargas, A. «Abandonar-se: el problema puro y la oportunidad moderna». En El hombre como solucionador de problemas, editado por J.F. Sellés. Pamplona: Servicio de Publicaciones de la Universidad de Navarra, 2015.

Enviado: 27 de febrero

Aceptado: 24 de abril de 2020 